Reprod. Nutr. Dévelop., 1988, 28 (1), 167-168.

\title{
Relation entre la fermentescibilité in vitro et la dégradabilité théorique in sacco de l'azote des aliments concentrés
}

\author{
P. CHAPOUTOT, D. SAUVANT, S. LEFRANC̣OIS
}

Station de nutrition et alimentation (I.N.R.A.) de I\%.N.A. - PG

16, rue Cl.-Bernard, 75231 Paris Cedex 05.

Summary. A set of 37 current concentrates and by-products was used to compare the data of nitrogen in vitro fermentescibility (F) and in sacco degradability (D). Mean values of D calculated for a particulate flow of $0.06 \mathrm{~h}^{-1}$ were rather close to the corresponding values estimated through the PDI system $(0.35+0.65 \mathrm{~F})$, however the hierarchy of individual values was in some case very different between the two methods.

Dans le système français des Protéines Digestibles dans l'Intestin (PDI), la dégradabilité ruminale de l'azote est évaluée à partir de sa fermentescibilité mesurée après $6 \mathrm{~h}$ d'incubation dans du liquide de rumen (Vérité et Demarquilly, 1978). Avec le même objectif, certains auteurs ont démontré l'intérêt de la mesure de la dégradation in sacco de l'azote (Stern et Satter, 1984), méthode qui tend à être de plus en plus adoptée. Cette étude a pour but de préciser sur un ensemble diversifié de matières premières, la relation entre les valeurs de fermentescibilité in vitro et de dégradabilité in sacco de l'azote.

Matériel et méthodes. Ce travail a été conduit sur 56 échantillons représentant 37 matières premières ou sous-produits : 5 céréales, 7 sous-produits de céréales, 2 protéagineux, 8 tourteaux, 1 luzerne déshydratée, 1 foin de luzerne, 12 sousproduits divers, 1 mélange de graines de soja et colza extrudées. Pour chaque aliment, la fermentescibilité de l'azote (F) a été mesurée par incubation in vitro en jus de rumen (Vérité et Demarquilly, 1978). La dégradabilité théorique de l'azote (DT6) a été calculée à partir des mesures de dégradation in sacco effectuées sur chèvres après $6,12,24$ et $48 \mathrm{~h}$ (30 échantillons), sur vaches après $2,4,6,12,24$ et $48 \mathrm{~h}$ d'incubation (22 échantillons) ou sur les 2 espèces (4 échantillons) selon la méthode décrite par Chapoutot, Hakim et Sauvant (1987) en tenant compte de la valeur de solubilité de l'azote dans une salive artificielle (Vérité et Demarquilly, 1978) pour $\mathrm{t}=1 \mathrm{~h}$ et d'un taux de renouvellement des particules dans le réticulorumen de $0.06 \mathrm{~h}^{-1}$.

Résultats et discussion. Les valeurs moyennes de fermentescibilité (F) obtenues sont comprises entre 3,4 et $86,3 \%$, tandis que les résultats moyens de dégradabilité théorique (DT6) varient de 23,9 à $89,5 \%$.

La figure 1 illustre la relation entre ces deux valeurs pour les 37 aliments :

$$
\text { DT6 }=44,3+0,49 \mathrm{~F} \quad(\mathrm{R}=0,59, \mathrm{ETR}=14,5)
$$

Si l'on compare les valeurs de DT6 au pourcentage d'azote dégradable estimée dans le système PDI à partir de la fermentescibilité $(=1-0,65(1-\mathrm{F}))$, il apparaît que la DT6 donne, en moyenne, des résultats légèrement supérieurs pour des aliments dont la fraction azotée est peu fermentescible (fig. 1). 
Pour 25 de ces matières premières, la comparaison de nos valeurs de $F$ avec les $F$ moyens publiés par Vérité et Sauvant (1981) aboutit à une corrélation de 0,84 ; l'écart-type résiduel (ETR) de 13,2 points s'explique en partie par la variabilité intra-matière première importante observée par ces auteurs et par l'insuffisance de reproductibilité et répétabilité de cette méthode. Les valeurs de DT6 obtenues sont très proches de celles de Madsen et Hvelplund (1985) sur 16 aliments : $\mathrm{R}=0,93, \mathrm{ETR}=7,5$, de $\mathrm{B}$. Michalet-Doreau (comm. pers.) sur 17 aliments : $\mathrm{R}=0,94$, ETR $=6,9$ et de Jacquot et Vedeau (comm. pers.) sur 21 aliments : $R=0,93, E T R=7,5$.

Cette étude effectuée sur un ensemble représentatif des concentrés et sousproduits les plus utilisés, indique que la substitution de la DT6 à la fermentescibilité modifie vraisemblablement peu les relations moyennes, par contre elle risque de modifier sensiblement la hiérarchie des valeurs azotées des différentes matières premières.

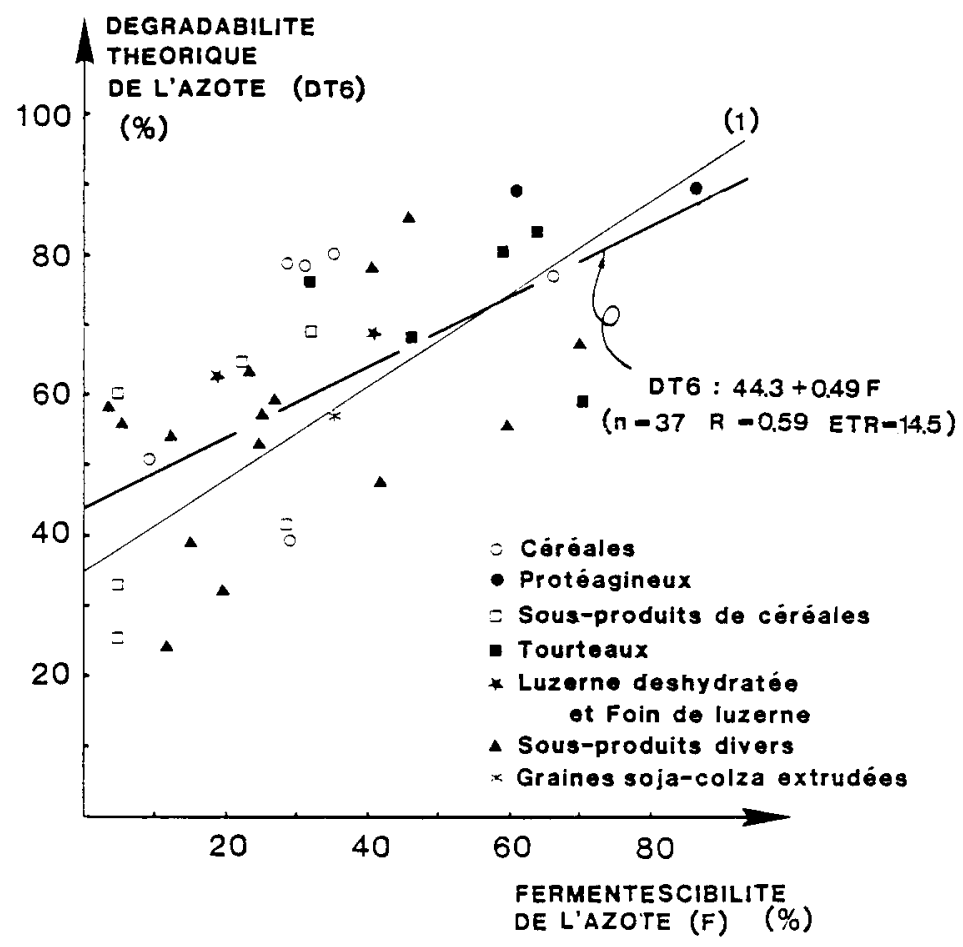

FIG. 1. - Relation entre la dégradabilité théorique et la fermentescibilité de l'azote.

(1) : Equation DT : $35+0,65$ F (I.N.R.A., 1978).

Chapoutot P., Hakim S., Sauvant D., 1987. Reprod. Nutr. Dévelop., 27, 265-266.

Madsen J., Hvelplund T., 1985. Acta agric. scand., Suppl. 25, 103-124.

Stern M. D., Satter L. D., 1984. J. anim. Sci., 58, 714-724.

Vérité R., Demarquilly C., 1978. In La vache laitière, pp. 143-157, Ed. I.N.R.A. Publ., 78000 Versailles.

Vérité R., Sauvant D., 1981. In Prévision de la valeur nutritive des aliments des Ruminants, pp. 279-296, Ed. I.N.R.A. Publ., 78000 Versailles. 